\title{
LOS REQUISITOS QUE CONFIGURAN LA "INTERVENCIÓN EN CONFLICTOS LABORALES" Y LA "INCITACIÓN A LA ALTERACIÓN DEL ORDEN PÚBLICO”, EN LAS CAUSALES DE CESACIÓN EN EL CARGO DE PARLAMENTARIO
}

\author{
THE REQUIREMENTS THAT MAKE UP THE INTERVENTION IN \\ LABOR DISPUTES AND THE INCITEMENT TO PUBLIC ORDER AT \\ THE CESATION'S CAUSES OF PARLIAMENTARY
}

Comentario de la sentencia del Tribunal Constitucional, de fecha 7 de octubre de 2008 (Rol N970-2007).

\section{Marcela Ahumada Canabes*}

\begin{abstract}
RESUMEN: El presente artículo analiza los principales aspectos y las conclusiones de la sentencia del Tribunal Constitucional, mediante la cual se resuelve el requerimiento presentado en contra de un senador para hacer efectiva su cesación en el cargo. Además, aprovecharé la oportunidad para efectuar algunas reflexiones en torno al papel que cumple el Tribunal Constitucional al resolver estas materias.
\end{abstract}

Palabras clave: Estatuto parlamentario, causales de cesación en el cargo de parlamentario, interpretación restrictiva, competencia del Tribunal Constitucional.

ABSTRACT: This work comments the main aspects of the sentence dictated by the Constitutional Court, which decide one requisition against a senator to declare the loss of the invested power. Furthermore the author considers some aspects about the competence of this Court on this matter.

Key words: Parliamentarians' Statute, loss of the invested power of paliamentary, restrictive interpretation, competence of Constitutional Court.

\section{INTRODUCCIÓN}

La sentencia del Tribunal Constitucional Rol No 970-2007, de fecha siete de octubre de 2008, dictada con ocasión de un requerimiento presentado contra el senador Alejandro Navarro Brain, se pronunció sobre la eventual vulneración en que habría incurrido el aludido parlamentario, a lo dispuesto en el artículo 60, incisos cuarto y quinto, de la Constitución Política de la República. Dicha norma, en lo que aquí

* Abogada, Magíster en Derecho Público, con mención en Derecho Constitucional por la Pontificia Universidad Católica de Chile; Doctora en Derecho por la Universidad Carlos III de Madrid; Profesora de Derecho Constitucional, Universidad Santo Tomás, sede Viña del Mar. E-mail: mahumadacan@yahoo.es 
interesa, consagra dos inhabilidades sobrevinientes o causales de cesación en el cargo de parlamentario: la intervención en conflictos laborales y la incitación a alteración del orden público. En un fallo unánime, el Tribunal Constitucional rechazó el requerimiento fundamentando claramente su decisión.

Los hechos, según se deja constancia en el requerimiento, consistieron en que el senador participó en una movilización convocada por la Central Unitaria de Trabajadores, CUT, que no había sido autorizada. En esa movilización, llevada a cabo en las inmediaciones de la Plaza Italia, el parlamentario encabezó una columna de trabajadores que intentó abrirse paso hacia el Palacio de La Moneda, por una calle donde el tránsito había sido prohibido por la autoridad correspondiente. Además, el parlamentario trató de impedir la detención del secretario general del Partido Comunista, maltratando de obra a carabineros, con golpes de pies y puños, manifestando a viva voz su condición de senador y presionando para que aquellos no cumplieran su labor. De esta manera se entiende habría ejercido influencias sobre la fuerza pública a favor de los trabajadores en el conflicto laboral que motivó la convocatoria. Asimismo, habría incitado al resto de los manifestantes a continuar su marcha hacia la Alameda, quebrando o pretendiendo quebrar la barrera dispuesta por Carabineros. Con esta última actuación habría incitado a la alteración del orden público, "tanto de quienes se encontraban con él en la Plaza Italia, como de los que, a través de la televisión pudieren verlo participando en un acto ilegal”.

En lo que sigue analizaré la forma en que el Tribunal Constitucional desarrolla su argumentación y aprovecharé la oportunidad, tanto para destacar la importancia de la sentencia que se comenta como para efectuar algunas reflexiones en torno al papel que cumple el Tribunal Constitucional en estas materias.

\section{TRASCENDENCIA DEL FALLO}

Antes de este requerimiento, las aludidas normas constitucionales no se habían invocado ante el Tribunal Constitucional, aunque habían ocurrido hechos que, eventualmente, podían configurar las causales de cesación allí descriptas. Por esta razón, el profesor José Luis Cea Egaña sostenía, hace unos años, que tales preceptos se habían convertido en normas programáticas, que habían "caído en desaplicación” o eran simplemente semánticas, pues solo mantenían la calidad de declamaciones, resintiendo la fuerza normativa de la Carta Fundamental ${ }^{1}$.

La determinación del significado de los enunciados que consagran las dos causales antes aludidas, es de gran importancia y sus implicancias políticas no son menores. Basta considerar que la sanción que aquellas llevan aparejada implica el término de un mandato representativo, es decir, la pérdida de la condición de parlamentario, cargo que es elegido por votación popular. De ello se deja expresa constancia en el fallo, al señalar que "la magnitud jurídica y política que reviste la aplicación de las causales en cuestión y su eventual acogida jurisdiccional" es evidente "pues afecta a autoridades de aquellas que el artículo $5^{\circ}$ de la Constitución hace depositarias del ejercicio de la soberanía que

${ }^{1}$ CEA (2001), p. 509. 
la Nación le entrega, y a las que el artículo 46 de la Carta les atribuye el principalísimo encargo de concurrir a la formación de las leyes, entre otras atribuciones igualmente esenciales en nuestro ordenamiento republicano democrático, que consagra el artículo $4^{\circ}$ de la Constitución" (considerando noveno. En similar sentido, también el considerando vigésimo noveno). Esta circunstancia, como veremos, será fundamental a la hora de resolver.

La existencia y subsistencia de estas causales de cesación en la Constitución Política de la República son cuestiones bastante controvertidas, no solo por el gran número de prohibiciones - una excepción en el Derecho comparado-, sino también por la competencia del órgano al cual se ha entregado la atribución de conocer y resolver sobre el asunto $^{2}$. Manifestación de ello han sido varios proyectos de ley que se han presentado al Congreso Nacional con el fin de modificar la Constitución en esta materia, aunque ninguno de ellos ha prosperado ${ }^{3}$.

La Constitución de 1925 consagraba también causales de cesación, pero con algunas diferencias. Eran menos y, además, su artículo 26, en el inciso $2^{\circ}$, entregaba a cada rama del Congreso la facultad de pronunciarse de manera exclusiva sobre las inhabilidades de sus miembros y para admitir su dimisión, si los motivos que la fundaren fueren de tal naturaleza que los imposibilitare física o moralmente para el ejercicio de sus cargos.

La Constitución de 1980 no solo agregó más causales, sino que, recogiendo las críticas al anterior sistema, que dejaba librada la suerte de los parlamentarios a mayorías circunstanciales, y entregó la facultad de pronunciarse sobre aquellas a un órgano distinto, el Tribunal Constitucional.

\section{LA INTERPRETACIÓN Y APLICACIÓN RESTRICTIVA DE LAS NORMAS QUE CONSAGRAN LAS CAUSALES DE CESACIÓN}

De manera previa a la determinación del sentido y alcance de cada una de las causales de cesación incluidas en el requerimiento, el supremo intérprete de la Constitución efectúa, en su pronunciamiento, una puntualización sobre el contexto normativo de aquellas, es decir, la integración de las normas en estudio dentro del denominado Estatuto Parlamentario o Estatuto de la Función Parlamentaria (considerando noveno).

\footnotetext{
2 En el ámbito latinoamericano, solo la Constitución de Colombia es tan estricta (art. 83). Vid. ZuLuaGA (2003). También se contemplan estas causales en la Constitución de Brasil (Art. 55) y en la Constitución de Uruguay (Art. 115).

3 Proyecto de reforma presentado por el senador Hosain Sabag Castillo, de 6 de junio de 2001 (Boletín 2724-07), que entre otras modificaciones, propone eliminar los incisos $4^{\circ}$ y $5^{\circ}$; el proyecto de reforma presentado por los senadores Chadwick, Espina, Moreno, Silva y Viera-Gallo, de 15 de mayo de 2003, que, entre otros asuntos, propone modificar la causal del inciso $5^{\circ}$ y eliminar la del inciso $4^{\circ}$ (Boletín 3241-07); y, finalmente, el proyecto de reforma presentado por el diputado Errázuriz, con fecha 18 de marzo de 1999, con el fin de modificar la causal relativa a las actuaciones de parlamentarios como abogados o mandatarios en juicios contra el Fisco o como procuradores o agentes en gestiones particulares de carácter administrativo, así como para entregar su conocimiento a cada una de las cámaras (Boletín 2311-07)
} 
Este es definido como "el conjunto de derechos, deberes y obligaciones establecidos por el derecho constitucional en orden a regular la actividad de los miembros del Congreso Nacional" ${ }^{4}$. Está constituido por el conjunto de normas comunes a los parlamentarios y comprende los requisitos de elegibilidad; las inhabilidades para ser elegido parlamentario; las incompatibilidades o prohibiciones para desempeñar simultáneamente tal misión con otras funciones retribuidas con fondos públicos; las prohibiciones de nombramiento o incapacidades; las inhabilidades sobrevinientes o una minuciosa lista de prohibiciones, cuya consecuencia es la cesación en el cargo aludido; y, finalmente, el establecimiento de privilegios, esto es, la inviolabilidad, la inmunidad parlamentaria y la dieta.

Ese cúmulo de prohibiciones, dentro del cual están comprendidas las causales en estudio y cuya infracción se sanciona con la cesación en el cargo, son el reflejo del recelo del Constituyente en la independencia de los parlamentarios así como del propósito de lograr un recto desempeño de sus funciones 5 .

La sentencia también hace alusión a la finalidad específica de la norma que consagra las causales de cesación, esto es, "por una parte, el deseo de deslindar la actividad parlamentaria de otros afanes sociales y económicos y por cierto políticos; considerados en ese momento de nuestra historia como ajenos a ella y excluyentes para sus ejecutores; y, por la otra, de sancionar severamente toda conducta que excediera el patrón democrático y de respeto por la institucionalidad que los parlamentarios deben a su propia investidura de representantes de la voluntad soberana en el marco de un Estado de Derecho" (considerando décimo).

Reiterando lo expresado en fallos anteriores sobre otras causales de cesación, especialmente en la sentencia Rol No 190, de 7 de diciembre de 1994, el Tribunal Constitucional sostiene que las normas que las consagran, como todo precepto de excepción, deben interpretarse restrictivamente. Esto, porque las prohibiciones parlamentarias son "limitaciones de derecho público", que afectan el ejercicio de los cargos de diputados y senadores y cuya infracción apareja como sanción la cesación en el cargo parlamentario". Por esta razón, agrega, su aplicación "debe dirigirse solamente a los casos expresa y explícitamente contemplados en la Constitución". No olvidemos que "se trata de preceptos de derecho estricto y no puede hacerse extensiva a otros, sea por similitud, analogía o extensión, conforme al principio de interpretación restrictiva de los preceptos de excepción" (considerando décimo) ${ }^{6}$.

La jurisprudencia constitucional, como se aprecia, ha adoptado un criterio de interpretación restrictivo de la potestad sancionatoria que el Tribunal Constitucional eventualmente puede ejercer respecto de los parlamentarios, rechazando las interpretaciones extensivas que pueden afectar el ejercicio de sus cargos.

\footnotetext{
${ }^{4}$ BRONFMAN (1993) p. 42.

5 CEA (1996).

6 STC 190-1994, considerando décimo. Similar pronunciamiento se contiene en otras sentencias del Tribunal Constitucional, relacionadas con el Estatuto Parlamentario, la Rol N ${ }^{\circ} 165$, de 19 de enero de 1993 (considerando noveno), que también recae en un requerimiento relacionado con aquel y, en términos amplios, esta en la sentencia 67, de 1989 (considerando séptimo).
} 
Además, ha debido considerar que la aplicación de las sanciones establecidas por la Constitución deben ser proporcional, razonable y no puede ser el fruto de una simple subsunción del supuesto de hecho en la norma. El criterio de proporcionalidad, en estos casos, supone ponderar o sopesar el costo de aplicación de la medida prevista por la norma, como su no aplicación, todo ello en relación con el cumplimiento de los fines de aquella. La razonabilidad, por su parte, implica una justificación racional.

La única cuestión que cuesta entender en esta parte del fallo, pues no se explica, es la alusión que se hace- en el considerando noveno- a un pretendido "efecto de irradiación de las causales de cesación en el Estatuto Parlamentario", expresión más ampliamente utilizada para aludir al efecto de los derechos humanos o de las normas que los consagran respecto de toda la Constitución.

\section{LA AMPLITUD DE LA ACTIVIDAD PARLAMENTARIA}

El Estatuto Parlamentario -los derechos, deberes y prerrogativas que lo conformanestá estrechamente relacionado con el mandato representativo que da origen a la posición jurídica parlamentaria, sin confundirse ni identificarse con aquel. El primero es la derivación instrumental de la "necesaria incorporación del representante al órgano que constitucionalmente asume la representación”, esto es, el Parlamento; mientras que el segundo, es el "producto de una relación de legitimidad democrática entre electores y elegidos"7.

En razón de esa estrecha relación es que el Tribunal Constitucional, al analizar las dos causales de cesación sometidas a su conocimiento, alude también a la representación, al mandato que ejercen los parlamentarios y a la praxis de la actividad parlamentaria. Así, en el desarrollo de su argumentación, el fallo se refiere a la extensión de la actividad parlamentaria, reconociendo que hoy en día esta "no se reduce a su labor dentro del hemiciclo, en las comisiones o en el marco de los deberes protocolares. Por el contrario, la participación de los parlamentarios en el proceso de elaboración de las leyes, así como en la labor fiscalizadora que le compete a la Cámara de Diputados, supone representar, en ambos casos, la opinión de sus mandantes: los ciudadanos; y el conocer su opinión incluye participar en aquellas modalidades en que aquellos tratan sus asuntos comunes en goce de las libertades y derechos que la Constitución reconoce" (considerando undécimo).

En apoyo a este argumento, el Tribunal Constitucional cita el informe elaborado por la Comisión de Constitución, Legislación, Justicia y Reglamento del Senado sobre la interpretación de los artículos 54 a 57, de fecha 14 de agosto de $1990^{8}$, en el cual se sostuvo que "el simple hecho de oír los planteamientos de una de las partes no configura la inhabilidad en comento".

Se trata, en estos casos, de analizar otras actuaciones de los parlamentarios, distintas a las que ejercen dentro del Parlamento. El Tribunal Constitucional no conoce aquí de actos emanados del Congreso Nacional, sino que debe determinar si determinadas

\footnotetext{
7 CAAMAÑO (1992) p. 125.

${ }^{8}$ Diario de Sesiones, tomo 320, p. 1597.
} 
Ahumada Canabes, Marcela "Los requisitos que configuran la ‘intervención en conflictos laborales’...”

conductas de miembros pertenecientes a él configuran infracciones a la Constitución, sancionadas con la cesación en el cargo.

\section{LA DETERMINACIÓN DEL CONTENIDO DE LOS ILÍCITOS CONSTITUCIONALES}

Como toda conducta que trae aparejada una sanción, los ilícitos constitucionales en que consisten las causales de cesación en el cargo de parlamentario o inhabilidades sobrevinientes, deben tener una descripción expresa en la normativa constitucional.

Al resolver el asunto planteado y para decidir si acoge o no el requerimiento, el Tribunal Constitucional debe determinar si los hechos aludidos en aquel configuran las conductas tipificadas por la aludida norma constitucional, especialmente en la parte relativa a la intervención en conflictos laborales y la incitación a la alteración del orden público. En otras palabras, debe establecer si la actuación del destinatario de la norma, el parlamentario, vulnera la norma constitucional, haciéndose acreedor de la sanción prevista para tales efectos.

La primera tarea del Tribunal Constitucional será, entonces, delimitar las conductas objeto del requerimiento, señalando aquellas actividades comprendidas en los incisos $4^{\circ}$ y $5^{\circ}$ del artículo 60 . Después de ello, procederá a determinar el significado de cada una de las dos causales invocadas y de las correspondientes "acciones punibles".

Finalmente, es del caso consignar que el fallo parecía relegar el criticado recurso a la historia fidedigna a un papel de simple antecedente histórico de la norma constitucional (considerandos sexto a octavo), pero conforme avanza en su razonamiento, acude a aquella para establecer la finalidad de la norma. Sin embargo, como se verá, en definitiva ella no será determinante al momento de zanjar la cuestión planteada al Tribunal.

\subsection{LA INTERVENCIÓN EN CONFLICTOS LABORALES EJERCIENDO INFLUENCIA} ANTE LA AUTORIDAD ADMINISTRATIVA A FAVOR DE LOS TRABAJADORES

El inciso cuarto del artículo 60 de la Constitución Política de la República, en su primera parte, contempla la causal de cesación relacionada con conflictos laborales junto a otra causal, relacionada con asuntos estudiantiles. La primera causal comprende varios supuestos. Por ello, el Tribunal Constitucional comienza por acotar los hechos respecto de los cuales se emitirá el pronunciamiento, esto es, solo se referirá al hecho de ejercer influencia, por un parlamentario, ante las autoridades administrativas (excluyendo a las judiciales) y a favor de los trabajadores (no comprende el hacerlo en su representación).

El fundamento específico de esta prohibición, que aparece consagrada por primera vez en nuestro ordenamiento en la Constitución de 1980, está tanto en la necesidad de impedir que los parlamentarios participen en la actividad sindical y especialmente en los conflictos que le son propios, como en evitar la politización del conflicto laboral?.

\footnotetext{
${ }^{9}$ La norma tiene como antecedente el artículo 31 del proyecto de reforma constitucional, presentado al Congreso en julio de1964, y el proyecto de reforma constitucional presentado por Frei en noviembre del mismo año. Vid. Bronfman (1993), pp. 84 y 85.
} 
El fallo invoca como fundamento de su interpretación la finalidad de la norma, que según se desprendería de la Sesión N 362 de la Comisión de Estudios de la Nueva Constitución ${ }^{10}$, es distinguir entre la actividad política y la gremial (considerando décimo).

El Tribunal Constitucional sostiene, en el considerando decimoséptimo, que para que se configure la causal contemplada en el artículo 60, inciso cuarto, primera parte ${ }^{11}$, se requiere que en la actividad del parlamentario concurran copulativamente tres circunstancias objetivas, que están relacionados con la naturaleza del conflicto, el tipo de autoridad ante el cual se actúa y la entidad de la influencia que se ejerce o pretende ejercer. Basta, sostiene, que falte cualquiera de ellas para que esta causal de cesación no se configure, lo cual armoniza con la interpretación restrictiva que debe aplicarse en estas inhabilidades sobrevinientes.

En primer lugar, se requiere que la influencia, que se ejerza por el parlamentario, se produzca "en el ámbito de negociaciones o conflictos laborales, esto es, de aquellos que enfrentan posiciones contrapuestas de empleadores y trabajadores, ya sea en torno a mejores condiciones de empleo o de remuneración".

El pronunciamiento no se refiere específicamente al significado de la actividad consistente en ejercer influencia, pero la literatura jurídica ha entendido que esta consiste en el acto de hacer valer la autoridad, poder o prestigio del parlamentario o de la corporación a que pertenece, expresando o manifestando activamente, por cualquier medio, su punto de vista, de manera que se convierta en un "medio de presión" que determina o condiciona el ejercicio de las atribuciones de autoridades independientes sobre un asunto determinado ${ }^{12}$.

Cuando la Comisión de Constitución, Justicia y Reglamento del Senado se pronunció sobre los requisitos que configuraban esta causal de inhabilidad, señaló que es necesario "que exista una participación activa del parlamentario en los mencionados conflictos o negociaciones, sea que esta se efectué ante el empleador o ante los trabajadores ${ }^{13}$.

\footnotetext{
10 Sobre las críticas a la interpretación que recurre a los debates de la Comisión de Estudios de la Nueva Constitución o Comisión Ortúzar, vid. ZAPATA (2008), pp. 193 y ss. Este organismo no sería el "constituyente", sino un órgano asesor, por tanto, no refleja la opinión del Constituyente, sino de sus asesores. Del mismo autor (2002), La jurisprudencia del Tribunal Constitucional. Parte General, Biblioteca Americana, Universidad Andrés Bello, Santiago, pp. 40-44. También, BASSA, Jaime (2008): El Estado Constitucional de Derecho. Efectos sobre la Constitución vigente y los derechos sociales, LexisNexis, Santiago, 2008, pp. 108 y $110-111$.

${ }^{11}$ Esta parte de la norma constitucional consagra dos causales de cesación en el cargo parlamentario, una relacionada con los conflictos laborales, y la otra, con las actividades estudiantiles.

12 Silva (2000), p. 329. "Solo si la influencia se emplea intencionalmente por cualquiera vía, se convierte en factor que puede determinar el resultado y transformarse en medio de presión llamado a condicionar el sentido que llegue a imponerse en el asunto".

${ }^{13}$ Se dejó constancia de que el simple hecho de oír los planteamientos de una de las partes no configura la inhabilidad en comento. Por el contrario, si el Parlamento hace cualquier gestión en esas materias incurrirá en la causal, aunque ella se haya hecho -o se aduzca haberla realizado- por razones de interés público o social. Informe de la Comisión de Legislación, Justicia y Reglamento del Senado, recaído en la consulta de la Sala sobre la interpretación de los artículos 54, 55, 56, 57 de la Constitución Política de la República, de fecha 31 de julio de 1990, aprobado por el Senado en Sesión de 7 de agosto de 1990. Boletín 516-10, p. 30.
} 
En segundo término, cualquiera sea la influencia, debe ejercitarse u operar "ante las autoridades administrativas o judiciales", las que, en virtud del principio de separación de órganos y de funciones, deben resolver siempre "con entera independencia de las Cámaras y de sus miembros" 14 . Dado que el requerimiento alude a la intervención del parlamentario ante carabineros, el Tribunal Constitucional precisa que las autoridades que interesan en el asunto sometido a su conocimiento son las administrativas, esto es, las que se encuentran consignadas en el artículo $1^{\circ}$, inciso segundo, de la ley $\mathrm{N}^{\circ} 18.575$, Orgánica Constitucional de Bases Generales de la Administración del Estado.

De acuerdo la disposición precedentemente citada, "la Administración del Estado estará constituida por los Ministerios, las Intendencias, las Gobernaciones y los órganos y servicios públicos creados para el cumplimiento de la función administrativa, incluidos la Contraloría General de la República, el Banco Central, las Fuerzas Armadas de Orden y Seguridad Pública, las Municipalidades y las empresas públicas creadas por ley”. En esta disposición se contiene una concepción amplia de la Administración Pública, que comprende a "todos los órganos y organismos del sector público, con la única excepción de aquellos que invisten una naturaleza legislativa o judicial" 15 .

En tercer lugar, en el mismo considerando se señala que esa influencia debe ser ejercida "en representación del empleador o de los trabajadores", vale decir, tomando partido a favor de uno u otro lado, "declarando y haciendo valer la preferencia, incluso como simple favor desinteresado [...] con mayor razón, asumiendo la representación o defensa de los que participan del conflicto"16.

Ahora bien, el Tribunal entiende que la intervención del parlamentario ante carabineros no se relaciona con un conflicto laboral, sino con el ingreso de los manifestantes a un sitio no autorizado (considerando vigésimo primero).

\subsection{LA INCITACIÓN A LA ALTERACIÓN DEL ORDEN PÚBLICO}

El artículo 60 enuncia, en el inciso $5^{\circ}$, varias conductas en que pueden incurrir los parlamentarios vinculadas con el respeto al orden institucional, similares a las contempladas por la Constitución respecto de otras altas autoridades como el Presidente de la República y los ministros de Estado, quienes pueden ser objeto de una acusación constitucional.

En la primera parte de la norma se sanciona la incitación a la alteración del orden público. Para determinar si la conducta invocada en el requerimiento resulta sancionable, el Tribunal Constitucional analiza y acota el significado de la expresión "orden público" y de las voces "alteración" e "incitar", utilizadas en el precepto constitucional.

La expresión "orden público" alude al bien jurídico constitucionalmente protegido y se menciona en diversas disposiciones de la Carta Fundamental, como los artículos 18 inciso $2^{\circ} ; 19 \mathrm{~N}^{\text {os }} 6,11,15$ y $21 ; 24 ; 42 ; 60$ y 101.

\footnotetext{
14 SiLVA (2000), p. 329.

15 PANTOJA (1987), p. 19.

16 SILVA (2000), p. 331.
} 
El orden público no es un término unívoco entre los autores. Por ello, para desentrañar su sentido, el Tribunal Constitucional acude al significado jurídico constitucional de esas palabras ${ }^{17}$ y lo entiende "según una concepción que guarde armonía con las demás oportunidades en las que el constituyente la emplea, es decir, considerando las relaciones de la norma invocada con los otros artículos de la Constitución Política o, lo que es igual, recurriendo a la interpretación sistemática (considerando vigésimo tercero).

Después de citar algunas definiciones dadas por los autores, el Tribunal Constitucional recurre a la noción de orden público conceptualizada por la jurisprudencia de la Corte Suprema, que ha entendido aquel en un sentido amplio, como "la tranquilidad y confianza social en el seguro desenvolvimiento pacífico de la vida civil" (parte final del considerando vigésimo cuarto $)^{18}$.

El Tribunal Constitucional entiende que esa concepción amplia otorga a este bien jurídico "un sitial muy importante en la normalidad de la vida cotidiana de la sociedad, en todas sus distintas dimensiones", lo que permite vincularlo, como requisito, al normal desenvolvimiento institucional, y por cierto jurídico del país" (considerando vigésimo quinto).

Para acotar la noción de orden público involucrada en la cuestión que debe resolver, el supremo intérprete requiere precisar el alcance de la voz "alteración”, y así, entiende que esta "es la acción de alterar", verbo que, a su vez, denota "cambiar la esencia o forma de una cosa" o "perturbar, trastornar, inquietar", acepción esta última que es la utilizada en la norma constitucional (considerando vigésimo quinto).

Por último, para la determinación del sentido de la voz "incitar", el Tribunal Constitucional acude al Diccionario de la Lengua Española de la Real Academia Española, aunque sin referirse expresamente a él. Según este, dicha voz significa "mover o estimular a uno para que ejecute una cosa", de manera que la prohibición en comento "se refiere a mover o estimular la ejecución de conductas que atenten contra el estado de tranquilidad y regularidad jurídica vigente en la sociedad"19.

Para el Tribunal, sin embargo, no es necesario apreciar si en la especie hubo o no incitación a la alteración del orden público, porque estima que no se dieron los supuestos para acreditar que el parlamentario incurrió en la conducta sancionada, señalando que más bien hay una adhesión y participación en una convocatoria.

Además, distingue dos acciones distintas, esto es la "participación” y la "incitación". Esta última, señala, debe ser "algo objetivamente grave" y debe acreditarse fehacientemente que ha ocurrido, ya sea de palabra o por escrito (considerando vigésimo

17 ZapaTA (2008), pp. 173-178. En la Constitución, las palabras pueden tener tres tipos de significados: el natural y obvio, que en nuestro ordenamiento se identifica con las definiciones del Diccionario de la Lengua Española de la Real Academia Española; el significado técnico, dado por la correspondiente ciencia o arte y, finalmente, el sentido jurídico constitucional.

18 ZAPATA (1986), p. 391. Se trata de una concepción amplia y subjetiva del orden público. Una concepción objetiva, en cambio, es aquella según la cual el orden público "denota la existencia armónica y pacífica de los ciudadanos bajo la soberanía del Estado y del Derecho". Subjetivamente, coincide con la definición de Alfredo Etcheberry.

19 BRONFMAN (1993), pp. 86-87. 
noveno). El asunto, en síntesis, se reduce a una cuestión de prueba, a un análisis de los hechos que se acreditaron durante el proceso a que dio lugar el requerimiento.

El Tribunal omite, en esta parte, una referencia a los medios a través de los cuales se exteriorizaron las expresiones que eventualmente pudieren incitar a la alteración del orden público, cuestión importante, porque optando por una interpretación restrictiva, hubiese permitido desestimar las alegaciones que aludían a la transmisión de los hechos a través de los medios televisivos. Ello por cuanto la norma constitucional alude a los que "de palabra o por escrito" hubiesen incitado a la alteración del orden público ${ }^{20}$.

\section{SOBRE LA COMPETENCIA DEL TRIBUNAL CONSTITUCIONAL}

La Constitución además de contemplar -en el artículo 60- las causales de cesación en el cargo de parlamentario, establece también el mecanismo y el órgano con competencia para resolver sobre las diversas infracciones al estatuto parlamentario.

En efecto, dentro del conjunto de competencias que la Constitución encomienda al Tribunal Constitucional, en el artículo $93 \mathrm{~N}^{\circ} 14$ le entrega a dicho órgano el conocimiento y resolución de las infracciones al artículo 60, consagrando, de esta manera, un sistema de control heterónomo de las prohibiciones parlamentarias ${ }^{21}$.

Al Tribunal Constitucional le corresponde pronunciarse sobre las inhabilidades sobrevinientes que afectan a un diputado o senador, que están expresamente establecidas en la Constitución, debiendo determinar en cada caso concreto si se configura o no alguna de esas causales de cesación respecto de algún parlamentario. Según lo dispuesto por el artículo $93 \mathrm{~N}^{\circ} 14$, el Tribunal conocerá de esta materia solo a requerimiento del Presidente de la República o de no menos de 10 parlamentarios en ejercicio.

El procedimiento y las garantías procesales que limitan el ejercicio de la potestad sancionatoria están establecidos en los artículos 51 a 62 de la Ley № 17.997, Orgánica Constitucional del Tribunal Constitucional, que contempla, por ejemplo, la notificación al requerido, el otorgamiento de un plazo de 10 días para su contestación; la recepción de la causa a prueba si se estima necesario, etc.

De acuerdo con el artículo 93, inciso penúltimo, cuando conozca, entre otras materias, sobre las causales de cesación de los parlamentarios, el Tribunal Constitucional podrá apreciar los hechos en conciencia, lo que "hace referencia a la libertad para evaluar el mérito probatorio de los hechos" 22 .

El Tribunal Constitucional, ya sabemos, conoce principalmente del control de constitucionalidad, pero además de otras materias -como la que aquí se analiza- que, en la taxonomía elaborada por los autores, están comprendidas dentro de otras competencias, también denominadas competencias residuales ${ }^{23}$.

\footnotetext{
${ }^{20}$ SILVA (2000), p. 356.

${ }^{21}$ CEA (1996).

22 BRONFMAN (1993), p. 99.

${ }^{23}$ Nogueira (2006), pp. 277 y 296.
} 
En nuestro ordenamiento jurídico, esta facultad del Tribunal Constitucional fue introducida por la Constitución de 1980, lo que importó un cambio radical que revolucionó el sistema de control del estatuto parlamentario ${ }^{24}$. Durante la vigencia de la Constitución de 1925, el pronunciamiento sobre las inhabilidades sobrevinientes de los parlamentarios era de competencia de las propias cámaras, mecanismo que en la práctica demostró sus inconvenientes. Pareciera más adecuado que su conocimiento y resolución estén entregados a un órgano políticamente neutral y mejor aún al guardián supremo de la Constitución. Esta atribución del Tribunal Constitucional ha sido objetada por algunos, por cuanto este órgano podría llegar a remover a los miembros del Parlamento que han sido elegidos democráticamente.

Ello por cuanto, en uso de sus atribuciones, el TC, que es un órgano constitucional, cuyos miembros son designados o elegidos por determinadas autoridades, puede poner fin al mandato representativo, es decir, disponer que los parlamentarios cesen en el cargo, independientemente de la decisión de los electores y del período de duración del respectivo cargo.

Ahora bien, me parece que con el fallo en comento y otros similares que aquí se han citado $^{25}$, el Tribunal Constitucional reafirma y evidencia las ventajas de la judicialización de la tutela de las normas prohibitivas que forman parte del estatuto de la función parlamentaria. Al entregar estas materias a un órgano independiente, se sustrae la decisión de manos de los órganos representativos, evitando los eventuales abusos que podrían producirse al interior de las cámaras, pues en el sistema anterior existía el riesgo de utilizar este mecanismo para alterar el resultado electoral, sin perjuicio de que los parlamentarios gozan también de garantías suficientes en su aplicación ${ }^{26}$.

\section{LA PRUEBA DE LAS CAUSALES DE CESACIÓN}

La doctrina ha advertido sobre la relatividad y las dificultades que presenta la apreciación de los hechos que configuran las causales de cesación, pues aunque aquellos pueden ser realizados con propósitos nobles y desinteresados, se corre el riesgo de configurar eventualmente alguna de estas causales ${ }^{27}$. Por esta razón, el Tribunal debe ser muy cauteloso al analizar los hechos que se someten a su conocimiento.

Como sabemos, cuando el Tribunal Constitucional conoce de las causales de cesación en el cargo de parlamentario, puede, de conformidad a lo dispuesto por el artículo 93, inciso penúltimo de la Constitución Política de la República, "apreciar los hechos en conciencia", lo que hace referencia a la libertad del Tribunal para evaluar el mérito probatorio de los hechos ${ }^{28}$.

24 BRONFMAN (1993), p. 95. Bajo la vigencia de la Constitución de 1925, cada cámara era competente para pronunciarse sobre la inhabilidad de sus miembros, que no estaba exenta de críticas por la imparcialidad.

25 Vid. nota 5.

${ }^{26}$ BLASCO (1997) p. 275. La opinión del autor se puede trasladar al ordenamiento chileno, aunque está pensada para el ordenamiento español, donde el asunto es resuelto por las cámaras, y el Tribunal Constitucional solo conoce de él por la vía del recurso de amparo.

27 QUINZIO (2004), p. 311.

${ }^{28}$ BRONFMAN (1993), p. 99. 
Después de determinar el sentido y significado de cada una de las causales en juego, el Tribunal Constitucional debe decidir la cuestión sometida a su conocimiento, que -como veremos- se reduce estrictamente a un problema de prueba. Esta actúa como límite al ejercicio de la potestad sancionatoria y sirve de garantía del debido proceso, sin perjuicio de constituir también una manifestación de la armonización de las competencias del tribunal con el principio de la "deferencia razonada", que debe imperar en sus relaciones con los distintos órganos del Estado, cuyos actos deben ser controlados ${ }^{29}$.

La prueba adquiere en estos asuntos un papel preponderante. El Tribunal debe formarse la plena convicción sobre los hechos acontecidos y denunciados en el requerimiento, que se tendrán por ciertos según se hayan acreditado.

En el caso en estudio, el Tribunal Constitucional concluye que las pruebas rendidas, apreciadas en conciencia, no son suficientes para dar por configuradas las conductas contempladas en las causales de cesación invocadas (considerandos vigésimo segundo y vigésimo noveno).

En la apreciación de los hechos concretos sometidos a su decisión, el Tribunal Constitucional concluye que no puede darse por acreditado que el parlamentario "haya observado una conducta que la Constitución describe como causal de destitución”, con mayor propiedad, causal de cesación en el cargo (considerando vigésimo quinto y trigésimo).

El Tribunal rechazó el requerimiento, tal como lo ha hecho en ocasiones anteriores, por entender que no concurren en la especie los supuestos contemplados por las normas constitucionales para configurar las causales de cesación. Sostuvo que, en este caso, "no se ha logrado identificar cuál es el conflicto laboral o el proceso de negociación colectiva en que se habría ejercido la influencia"; que no existió un conflicto entre carabineros y los manifestantes, al menos en el sentido que sanciona la norma; que "no puede entenderse que el senador requerido "haya intercedido a favor de los trabajadores ante una autoridad administrativa ni tampoco que su intervención ha ocurrido en el contexto de un conflicto laboral" (considerandos decimoséptimo y vigésimo segundo).

De la misma manera, tampoco puede sostenerse que haya habido incitación al orden público, pues este debe "tratarse de algo objetivamente grave" y diferente de la "participación” en aquella (considerando vigésimo noveno).

En la otra sentencia del Tribunal Constitucional antes citada, Rol Nº 190-1994, los ministros Jiménez y Colombo, que concurren con su voto, sostuvieron -letra a) - que la atribución del Tribunal Constitucional de pronunciarse sobre las causales de cesación "es de tal trascendencia e importancia que el o los hechos o conductas ilícitas que son constitutivos de la o las causales de inhabilidad que pueden invocarse y que acarrearían la cesación en el cargo de parlamentario en ejercicio a quien se le imputan deben acreditarse fehacientemente, de manera tal que no haya duda para el sentenciador, no obstante la apreciación en conciencia que puede hacer de ellos, de la procedencia de la aplicación de la sanción, y en especial si se tiene en consideración que en el requeri-

29 ZAPATA (2002), pp. 69-72. También el mismo autor (2008), pp. 225 y ss. Solo se refiere a la deferencia razona en el ámbito del control de las leyes. 
miento entablado se pretende afectar diversos derechos fundamentales reconocidos en la Constitución"30.

La prueba adquiere un papel preponderante en estos asuntos. El Tribunal no solo debe determinar el sentido de las normas invocadas sino también adquirir la convicción sobre cuáles son los hechos, contenidos en el requerimiento, que han sido probados y que se dan por ciertos.

Además de lo anterior, el Tribunal efectúa una ponderación de los costos de aplicación de una medida, como la cesación en el cargo parlamentario; la gravitación de la medida en un sistema democrático; la amplia descripción que las normas constitucionales hacen de las conductas sancionadas y los hechos que han resultado acreditados, todo lo cual (considerando vigésimo noveno), le lleva a concluir que el requerimiento debe ser desestimado.

\section{CONCLUSIONES}

Esta es la primera sentencia del Tribunal Constitucional sobre las causales de cesación consistentes en la intervención en conflictos laborales y la incitación a la alteración del orden público, contenidas en el artículo 60 de la Constitución Política de la República, pues no se habían sometido a su conocimiento situaciones como las planteadas en el requerimiento que dio lugar al fallo en comento. El Tribunal Constitucional ha precisado y acotado, en esta oportunidad, el contenido de aquellas, cuyos enunciados se caracterizan por estar formulados en términos amplios y vagos.

El efecto de la admisión del requerimiento, hace efectiva la sanción prevista en las referidas causales, esto es, es el término del mandato representativo o la pérdida del cargo parlamentario. La magnitud de esa sanción, esto es, privar al parlamentario de su

${ }^{30}$ Los derechos que eventualmente podrían verse afectados son los contenidos en el artículo $19 \mathrm{~N}^{\circ} 17$-el derecho a acceder a las funciones y empleos públicos sin otros requisitos que los que impongan la Constitución y las leyes y que comprende también el derecho a permanecer en dichos cargos y funciones- y el derecho reconocido en el artículo 13, inciso segundo, de la Carta Fundamental, esto es, el de participar en los asuntos públicos por medio del sufragio u optando directamente a un cargo de elección popular. Agregan, a continuación los ministros, que "cuando a un órgano previsto en la Constitución, como el Tribunal Constitucional, se le ha dado la autoridad para hacer cesar en el cargo a un parlamentario en ejercicio, en los casos que la Carta Fundamental señala, constituye una situación excepcional y extraordinaria, que debe se fehacientemente acreditada". Esta postura de los ministros, alude a la representación política desde la óptica de los derechos fundamentales, es decir, incorpora a esta una dimensión democrática, que no ha sido asumida por el Tribunal Constitucional en fallos posteriores. Vid., en este sentido, CAAMAÑO (1992), especialmente pp. 127 y ss. El no asumir esa postura es acertado, porque esa tesis del voto concurrente no es comúnmente aceptada por los autores, principalmente en razón de que los pretendidos "derechos de los parlamentarios en cuanto tales" únicamente debería reconducirse a los derechos aludidos en los artículos 13 y $19 \mathrm{~N}^{\circ} 17$. Y ello porque el catálogo de derechos contenidos en la Constitución "no es el estatuto del poder, sino de la libertad, y la garantía de esta pierde buena parte de su sentido, o todo él, al proyectarla sobre el modo de organización y funcionamiento de las instituciones públicas". JiMÉNEZ, Javier, (1997) "Sobre los derechos fundamentales de los parlamentarios", en PAU I VALL, Francec (coord.), Parlamento y Justicia Constitucional. IV Jornadas de la Asociación Española de Letrados de Parlamentos, Aranzadi, Navarra, p. 220. Esos son, con más propiedad, derechos de los representados y derechos funcionales del representante (p. 225). 
función, aconsejan decidir con cautela la que el Tribunal Constitucional ha demostrado en esta oportunidad y en otras en las que ha conocido de asuntos similares.

En una decisión unánime, el Tribunal Constitucional concluye que las actuaciones del parlamentario no conculcaron las normas constitucionales, es decir, que las conductas desplegadas por aquel no son subsumibles en los ilícitos constitucionales contemplados en el artículo 60, incisos cuarto y quinto, de la Carta Fundamental.

Un fallo como el de la especie legitima el papel del Tribunal Constitucional, más aún cuando se ha cuestionado su competencia para conocer de estos asuntos, que a juicio de algunos deberían entregarse al conocimiento y resolución de las propias cámaras, aunque estas, obviamente, resolvería con un criterio más político que jurídico. Una sentencia como la que se comenta viene a demostrar que la solución del Constituyente de 1980 ha sido la acertada. El Tribunal Constitucional, dadas sus particularidades de independencia, imparcialidad y neutralidad, es el órgano adecuado para conocer de este tipo de controversias y ha demostrado con esta y otras sentencias sobre las causales de cesación en el cargo parlamentario, que la decisión de estos asuntos es indudablemente jurídica. Además, el mecanismo establecido en la Constitución ha resultado eficaz y contempla garantías de un justo procedimiento.

En el plano de constitucione ferenda me parece que sería conveniente la revisión y discusión de estas causales o que las sanciones fueran menos graves. Es indudable que estas prohibiciones ameritan una revisión y una reforma constitucional, especialmente en orden a disminuir su número. Mientras ello no ocurra, el Tribunal Constitucional, con la sentencia en comento y otras similares, ha dado muestras suficientes de objetividad, imparcialidad y razonabilidad.

\section{BIBLIOGRAFÍA CITADA}

Blasco JÁuregui, Jerónimo (1997): “Adquisición, suspensión y pérdida de la condición de parlamentario", en PAUl I VALL, Francesc (Coord.), Parlamento y Justicia Constitucional. IV Jornadas de Asociación Española de Letrados de Parlamentos (Navarra, Aranzadi), pp. 261-276.

Bronfman Vargas, Alan; De la Fuente Hulaud, Felipe y Parada Espinoza, Fernando (1993): El Congreso Nacional. Estudio Constitucional, Legal y Reglamentario (Valparaíso, Centro de Estudios y Asistencia Legislativa), 556 pp.

CAAMAÑO, Francisco (1992): "Mandato Parlamentario y derechos fundamentales (Notas para una teoría de la representación "constitucionalmente adecuada")", en Revista Española de Derecho Constitucional, Año 12, No 36, septiembre-diciembre, pp. 123-149.

CEA EgAÑA, José Luis (2001): "El parlamentario en la Constitución, en Navarro Beltrán, Enrique (coord.), 20 años de la Constitución Chilena (Santiago LexisNexis), pp. 501-516.

CEA EgAÑA, José Luis (1996): "El sistema de gobierno chileno", en Revista de Derecho de la Universidad de Valdivia, vol. VII, pp. 7-46. Disponible en http:// mingaonline.uach.cl/scielo.ph p?script=sci_arttext \&pid=S07 18 $09501996000100001 \& \operatorname{lng}=$ es\&nrm=iso (Consultado 4 de septiembre de 2009). 
JimÉnEZ CAMPO, Javier (1997): "Sobre los derechos fundamentales de los parlamentarios”, en PAU I VAll, FranCESC (Coord.), Parlamento y Justicia Constitucional. IV Jornadas de la Asociación Española de Letrados de Parlamentos, Aranzadi, Navarra, pp. 219-231.

Nogueira AlCalÁ, Humberto (2006): "La ampliación de las competencias de control de constitucionalidad del Tribunal Constitucional chileno y la ampliación de la fuerza normativa de sus sentencias de acuerdo con la reforma constitucional de 2005”, en Revista Iberoamericana de Derecho Procesal Constitucional, $\mathrm{N}^{\circ}$ 6, julio-diciembre de 2006, pp. 275-297.

Pantoja BauzÁ, Rolando (1987): Bases Generales de la Administración del Estado (Santiago, Editorial Jurídica Ediar-ConoSur Ltda.), 180 pp.

QuinZio FigueIREDO, Jorge Mario (2004): Tratado de Derecho Constitucional, Tomo II (Santiago, LexisNexis), 606 pp.

Silva Bascuñán, Alejandro (2000): Tratado de Derecho Constitucional, tomo VI, Congreso Nacional (Santiago, Editorial Jurídica de Chile), 424 pp.

Zapata Larraín, Patricio (1986): "El derecho a disentir ante la ley penal", en Revista Chilena de Derecho, vol. 13, pp. 383-404.

Zapata Larraín, Patricio (2002): La jurisprudencia del Tribunal Constitucional, Parte General (Santiago, Biblioteca Americana, Universidad Andrés Bello) 200 pp.

Zapata LARRAÍn, Patricio (2008): Justicia Constitucional. Teoría y práctica en el Derecho Chileno y comparado (Santiago, Editorial Jurídica de Chile), 623 pp.

\section{NORMAS CITADAS}

Constitución Política de la República de Chile. Texto refundido, coordinado y sistematizado por el Decreto $\mathrm{N}^{\circ}$ 100. Diario Oficial de 22.09.2005, especialmente artículos 60 y 93 .

Constitución Política de la República de Chile, de 1925. Diario Oficial de 18 de septiembre de 1925.

Ley $\mathrm{N}^{\circ}$ 18.575, Orgánica Constitucional de Bases de la Administración del Estado.

\section{JURISPRUDENCIA CITADA}

Requerimiento formulado por diversos diputados para que el Tribunal declare la inhabilidad de los senadores que señalan, de acuerdo al artículo $82 \mathrm{~N}^{\circ} 11$, de la Constitución Política de la República, Rol N 165, de 19 de enero de 1993. Disponible en: http://www.tribunalconstitucional.cl/index.php/sentencias/download/pdf/449 20-11-2009.

Requerimiento formulado por diversos senadores para que el Tribunal declare que el senador de la República don Francisco Javier Errázuriz Talavera ha incurrido en la causal de cesación en el cargo contemplada en el artículo 57 , inciso $2^{\circ}$, última parte, e inciso tercero de la Carta Fundamental, de acuerdo al artículo $82 \mathrm{~N}^{\circ} 11$ de la Constitución Política de la República, Rol N 190, de 7 de diciembre de 1994. 
392 Revista Chilena de Derecho, vol. 37 N² 2, pp. 377 - 392 [2010]

Ahumada Canabes, Marcela — "Los requisitos que configuran la 'intervención en conflictos laborales'...”

Disponible en: http://www.tribunalconstitucional.cl/index.php/sentencias/download/ pdf/426 20-11-2009. 